\title{
No hugging please, we are Muslims': Akademi Fantasia, Malay television audiences and the negotiation of global popular cultural forms
}

\begin{abstract}
This paper analyses the audience reception of the Malaysian reality television programme Akademi Fantasia (AF), which first aired in 2003 and completed its ninth season in 2011. AF has been an influential pioneer in the national television industry, inaugurating the trend of local reality shows and weathering intense competition from similar shows to remain at the top of the ratings chart over the last decade. Based on the Mexican talent search show, La Academia, Malaysia's AF is a unique hybrid blend of an Idol-style talent contest and Big Brother observational spectacle. The article draws on primary audience research to investigate the ways in which Malay audiences interpret the potentially incommensurable cultural meanings generated within the context of a localised version of a global television format. Chua's concept of 'identification and distancing' is employed as a framework to analyse the complex ways in which perceived Malay 'cultural norms' assume primacy as interpretative lenses for audience evaluations of the show and measures of its local difference from similar global cultural products. The research also reveals how these cultural norms are themselves being negotiated by the audience as part of the everyday experience of inhabiting coexisting local and global popular cultural spaces. The analysis focuses on audience understandings and pleasure in the programme in relation to fashion and taste; the behaviour of the official judges; voyeurism and conflict in 'backstage' coverage; and emotional intimacy onstage in the public performance component of the programme.
\end{abstract}

Keyword: Reality TV; Audience reception; Malaysia; Globalisation; Popular culture 